\title{
WACANA PATRIOTIK WANITA DALAM DUNIA SAMURAI: SEBUAH ANALISIS WACANA KRITIS PADA DORAMA
}

\author{
S.W. Widiati ${ }^{1}$ \\ ${ }^{123}$ Prodi Pendidikan Bahasa Jepang, FKIP, Universitas Riau, Pekanbaru \\ e-mail: wiwid.sw.widiati@gmail.com
}

\begin{abstract}
Abstrak
Fenomena patriotisme wanita Jepang mendorong dilakukannya kajian terhadap drama TV atau dorama bernuansa sejarah berjudul Byakkotai. Penelitian ini bertujuan untuk menelaah bahasa tokohtokoh wanita berdasarkan perspektif feminisme. Analisis Wacana Kritis Feminisme digunakan sebagai metode penelitian untuk mengkaji konteks sosial dan budaya yang dihubungkan dengan paradigma transformasi gender. Hasil penelitian ini menunjukkan karakter lima tokoh penting wanita dalam Byakkotai berdasarkan peran dan kontribusi mereka berjuang bersama kaum pria.
\end{abstract}

Kata kunci: analisis wacana kritis feminisme, tokoh wanita, karakter, drama.

\begin{abstract}
The phenomenon of Japanese women's patriotism has prompted a study of a historical TV Drama or dorama entitled Byakkotai. This study aims to examine the language of female characters based on a feminist perspective. Feminist Critical Discourse Analysis is used as a research method to study the social and cultural context associated with the gender transformation paradigm. The results of this study indicate the characters of the five female of the Aizu Clan in the Byakkotai based on their roles and contributions to struggle with men.
\end{abstract}

Keyword: feminist critical discourse analysis, women, characters, drama.

\section{Pendahuluan}

Riset mengenai bahasa dapat menembus zaman, menarik pelajaran dari masa lampau dan memberikan manfaat pengetahuan bagi masa seterusnya. Gender dan bahasa menjadi suatu kajian penting untuk melihat fenomena historis. Gender didefinisikan sebagai suatu kategori sosial yang terkait dengan kategori-kategori sosial lainnya yang meliputi identitas sosial, jenis kelamin, suku, umur, kemampuan, kelas dan posisi sosial, serta lokasi geografi (Lazar,2007:141).

Jepang merupakan suatu bangsa dengan sejarah panjang yang memiliki nilai budaya tinggi dan aspek kebahasaan yang berkarakter. Sebagaimana yang kita ketahui dalam pengetahuan bahasa Jepang kontemporer, Jepang memiliki bahasa pria (otoko no kotoba) dan bahasa wanita (onna no kotoba). Namun, bila menggunakan kaca mata sejarah, maka bahasa dan gender dalam bahasa Jepang dapat merepresentasikan makna yang lebih dalam. Jepang mengalami berbagai dinamika aspek bahasa terkait gender. Terdapat masa di saat simbol wanita sangat agung yaitu disembahnya Dewa Matahari bernama Amaterasu sebagai dewa tertinggi yang merupakan dewa wanita. Kemudian bergeser pada ketimpangan gender, seperti ketika seni bernilai sastra yaitu Kabuki yang semula diperankan oleh wanita, berubah diperankan oleh pria. Masih banyak lagi hal yang menarik untuk dikaji terkait bahasa dan gender dalam sejarah Jepang.

Untuk mengulas bahasa dalam sejarah, diperlukan suatu media yang dapat membantu melukiskan kehidupan masa lalu seperti film, drama TV, novel dan sebagainya dengan konten sejarah. Penelitian ini memilih drama TV yang mengisahkan sejarah. Drama 
tersebut berjudul Byakkotai (白虎隊). Dalam bahasa Indonesia bermakna Pasukan Harimau Putih. Terdapat beberapa versi drama atau film Byakkotai, penelitian ini memilih drama Byakkotai yang dirilis tahun 2007.

Byakkotai mengisahkan sejarah zaman Edo tentang sebuah pasukan samurai muda yang berjuang mempertahankan kekuasaan wilayah Aizu pada Perang Boshin. Para samurai muda yang dimaksud merupakan para murid baru di sekolah samurai Nisshinkan, namun dikarenakan pecahnya perang dan Klan Aizu kekurangan pasukan, maka meskipun masih berusia muda, mereka ditugaskan ke medan perang.

Selama mengikuti pendidikan calon samurai, terdapat sejumlah aturan ketat termasuk mengenai aturan berkomunikasi dengan wanita. Hal tersebut mencerminkan terbentuknya stereotipe wanita dan perlakuan yang tidak sama terhadap semua wanita. Negara Jepang pada zaman tersebut masih sangat dipengaruhi dominasi politik dan otoritas kaum pria dalam mengatur norma dan struktur sosial. Dalam drama Byakkotai, peran, karakter, dan gaya bahasa para tokoh wanita berciri khas masing-masing, tetapi memiliki visi yang sama yaitu berkontribusi untuk menyalakan semangat perjuangan. Pada satu sisi terjadi degradasi citra wanita, namun pada satu sisi citra wanita dapat berada pada tingkatan tinggi meskipun diatur dalam kultur patriarki.

Penelitian ini bertujuan memaparkan mengenai kajian feminisme terkait gambaran sosial yang terkandung di balik bahasa yang digunakan tokoh wanita pada drama Byakkotai.

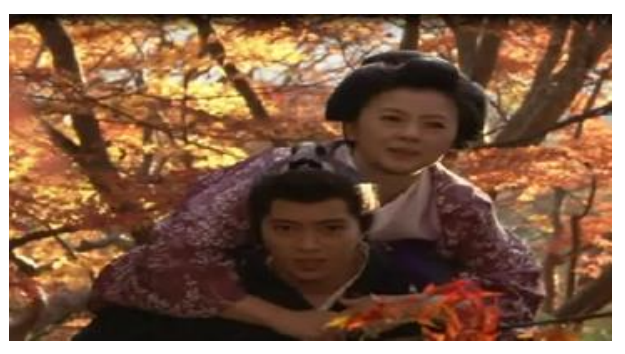

Gambar 1. Adegan dalam Film Byakkotai

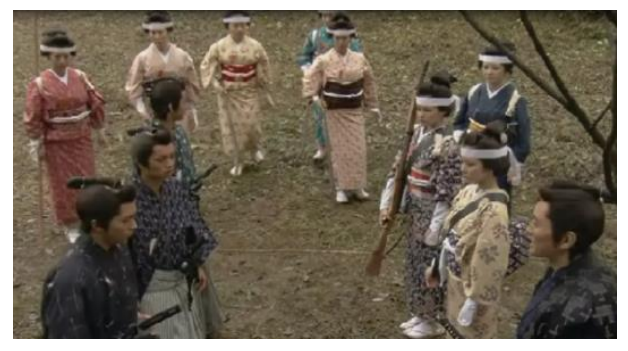

Gambar 2. Adegan dalam Film Byakkotai

\section{Kajian Teori}

Wacana gender yang menjadi pembahasan pada penelitian ini tidak berada pada tataran linguistik formal. Sebagaimana definisi wacana dalam pandangan konteks yaitu penggunaan bahasa dalam situasi-situasi sosial, tidak merujuk pada bentuk-bentuk linguistik yang ideal dan formal, namun turut menjadi suatu bagian dalam fenomena kehidupan manusia yang lebih luas (Bucholtz via Holmes,2003:44-45). Dalam AWK Feminisme, konteks dapat dijelaskan dalam beberapa cara: dapat melibatkan teks linguistik, genre, situasi sosial, termasuk hubungan khusus (gender) antar partisipan, pertimbangan fisikal secara khusus, dan asumsi budaya (Lehtonen,2007:9).

Analisis Wacana Kritis digunakan untuk menelaah hubungan dialektika antara bahasa pada film yang diangkat sebagai objek penelitian ini dengan situasi sosial yang dihadapi kaum wanita. AWK menggunakan bahasa untuk memahami ideologi dan budaya, serta hubungan antara sosial dan politik (Bucholtz via Holmes,2003:57). Hal tersebut menunjukkan adanya fungsi untuk mempertahankan, memproduksi, atau mentransformasi status sosial maupun status quo (Titscher,et al.2009:44). Dinamika sosial yang tidak mungkin berhenti menjadikan ranah bahasa dan gender terus menjadi objek studi dan diskusi dalam ilmu-ilmu sosial. Demikian halnya, bahasa wanita tidak akan mengalami 
stagnansi sepanjang waktu. Pergeseran gaya bahasa bernuansa gender memunculkan berbagai pendekatan konstruktif (Stokoe\& Weatherall,2002:707). Untuk menfokuskan kajian pada peran dan karakter tokoh-tokoh wanita, maka AWK pada penelitian ini lebih spesifik menjadi Analisis Wacana Kritis Feminisme (Feminist Critical Discourse Analysis - FCDA) yang merujuk pada teori yang diajukan teoris Feminis Michelle M. Lazar (2007).

AWK Feminisme merupakan studi interdisipliner yang berkontribusi terhadap perkembangan bahasa dan wacana, serta bermanfaat bagi kemajuan studi mengenai wanita. AWK Feminisme berfokus pada keadilan sosial dan transformasi gender. Di bawah payung AWK, studi yang dilakukan terhadap relasi politik, kekuasaan, dan gender dalam wacana ini turut menunjukkan fenomena strategi politik dan perubahan sosial (Lazar,2007:142-143). AWK Feminisme mencoba mengungkap perubahan persepsi gender yang temuat dalam teks maupun percakapan, sehingga bermanfaat bagi kesetaraan perlakuan antara pria dan wanita.

Kajian terhadap wacana kaum wanita sering menunjukkan adanya fakta diskriminasi. Sebagaimana yang diugkapkan Kramarae bahwa sejarah menunjukkan fenomena bahasa yang dikonstruksi oleh kaum dominan pria, sehingga wanita tidak memiliki cukup akses, serta norma berkomunikasi tidak berlaku setara. Kramarae menyebut kondisi wanita tanpa hak berbicara sebagai cara kerja kelompok terbungkam atau muted group framework (Elgin,1982:941). Yang dimaksud adalah kelompok subordinat yaitu wanita dan anak diatur untuk tidak berartikulasi, melainkan hanya mengadaptasi ide dan persepsi kaum pria. Pekerjaan, pembicaraan, dan kenginginan kelompok subordinat ini tidak dianggap penting. Oleh karena itu, AWK Feminisme hadir untuk memberikan kritik holistik terhadap konstruksi yang tidak adil dan diskursif terhadap gender (Lazar,2007:145).

\section{Metode}

Penelitian ini menggunakan metode penelitian kualitatif yang berupa analisis wacana kritis. Peneliti kualitatif diharapkan mampu untuk mengevaluasi dan menentukan tindakan yang perlu diambil guna memperoleh pengetahuan yang lebih luas dari suatu konteks. Penelitian kualitatif merupakan jenis penelitian yang sangat sesuai untuk mengetahui konteks dan data yang dihasilkan bersifat deskriptif (Tracy,2013:4-5). Analisis wacana film pada penelitian ini diakukan dengan cara memilih teks-teks yang dinilai mencerminkan karakter tokoh wanita, lalu menginterpretasikan teks-teks tersebut.

Analisis tekstual dalam AWK Feminisme bertujuan untuk menghubungkan antara representasi gender yang satu dengan lainnya, atau menghubungkan wacana gender dengan konteks sosial maupun budaya. Tetapi AWK Feminisme tidak mengkaji hingga domain respon pembaca atau pemirsa (Lehtonen,2007:6). Peneliti feminisme pada umumnya menerapkan kajian konteks sosial seperti teori Foulcault dan menggunakan model Fairclough dalam metode analisis wacana kritis (Lehtonen,2007: 6-7). Pada penelitian ini, proses analisis wacana kritis hanya mengadaptasi proses analisis praktik sosial budaya dari model Fairclough. Hal ini atas dasar proses analisis praktik sosial budaya yang akan dipaparkan telah mencakup aspek teks dan wacana, selain itu agar konteks feminisme dapat lebih terfokus.

\section{Hasil Penelitian}

1. Tokoh Wanita 1 : Shige

Shige merupakan ibu dari Sakai Mineji. Tokoh Shige mencerminkan keteguhan hati seorang ibu untuk membentuk pribadi putranya untuk menjadi seorang samurai yang rela mati demi Klannya yaitu Klan Aizu. Shige merupakan seorang ibu yang sengaja mendidik putranya secara keras dan dingin.

Kalimat yang selalu diucapkan Shige adalah 「会津武士として役に立ち、立派に死ぬ ことを心掛けなさい」(Ingatlah selalu untuk menjadi bermanfaat sebagai prajurit Aizu, dan mati dengan terhormat). Shige menganggap bahwa dengan tutur kata yang dingin dan kalimat yang diulang-ulang tersebut dapat membuat Mineji tidak melupakan tugas utamanya sebagai samurai. 
JPBJ, Vol. 7 No. 1, Februari 2021

ISSN: 2613-9618

Kalimat senada sering diucapkan Shige dalam berbagai kesempatan, seperti ketika memarahi Mineji. 「お前は会津を守り、殿様と天子の扱いし、武士として立派に働き、立派 に死ぬために日清間に学んでおるのだ。母に紅葉を見せるより、立派な会津武士になること が大切のじや。はよう帰って日清間に行け、紅葉などどうでも良えば。はよう。ならぬこと はならぬのじゃ」(Kau belajar di Nisshinkan untuk melindungi Aizu, mengabdi pada Tuan dan Kaisar, bekerja dengan hebat sebagai prajurit, dan mati dengan wibawa. Ayo cepat pulang, pergi ke Nisshinkan, tidak penting melihat momiji. Cepat. Lakukan apa yang wajib kau lakukan). Tidak bosannya Shige mengingatkan Mineji agar bersiap berjuang dan gugur demi Aizu menunjukkan adanya sikap patriotik dalam diri Shige. Shige menyadari bahwa kondisi tubuhnya yang sangat lemah dapat saja membuat dirinya gagal membentuk Mineji menjadi seorang prajurit tangguh, sehingga ia memilih bertindak keras melalui verbalnya.

Shige kerap mengacuhkan dan menyalahkan Mineji seperti pada dialog「疲れた。話 なら、あとで聞く」(Aku lelah. Jika ingin berbicara, nanti saja) atau pada dialog 「母のせい にするでない。この子はいつもこうじや」 (Jangan salahkan ibu. Anak ini memang selalu seperti ini). Hal itu ia lakukan agar Mineji tidak tumbuh menjadi manja dan selalu dapat berinterospeksi. Shige ingin putranya menjadi pemberani dan sanggup mempertaruhkan nyawa demi Klan Aizu. Shige menyadari bahwa seluruh rakyat terutama keluarga samurai, bertanggungjawab menjaga Aizu di atas apapun.

Shige secara sengaja membuat citra diri sebagai seorang ibu yang sama sekali tidak memperhatikan Mineji meskipun sebenarnya ia sangat menyayangi putranya. Shige memiliki otoritas yang kuat dikarenakan ia seorang ibu, ditambah lagi ia memiliki tanggung jawab yang besar untuk mendidik putranya untuk siap bertarung. Bagi Shige, perasaan pribadi terlalu kecil dibandingkan rasa tanggung jawab terhadap Klan Aizu. Rahasia kepribadiannya yang sesungguhnya dapat diketahui melalui kalimat yang diucapkan Shige yaitu「私は峰地 に冷たく当たる理由は誰も知る必要がありません」(Alasanku bersikap dingin pada Mineji, siapapun tidak perlu mengetahuinya).

Sikap Shige terhadap Mineji tetap membuat Mineji menjadi putra yang patuh dan menyayangi ibunya. Namun, selalu ada perasaan kecil hati karena ia merasa tidak disayangi sebagaimana mestinya. Saat perang Boshin berlangsung, Mineji dan Matahachi terpisah dari pasukan. Dikarenakan situasi sangat genting, mereka memutuskan menyamar menjadi petani dan kembali pulang untuk membantu di wilayah Aizu. Mineji merasa tidak tepat merasa rendah jika berpakaian layaknya petani meskipun mereka adalah samurai, karena semua orang hidup punya harga diri dan hak untuk hidup. Tetapi setiba di Aizu mereka tetap menyampaikan rasa penyesalan tidak dapat meneruskan perjuangan bersama Byakkotai lainnya di medan perang. Saat menemui Shige, seketika Shige berubah sikap dengan menunjukkan rasa betapa ia bersyukur Mineji masih hidup. Shige menyadari bahwa saat perang benar-benar telah pecah, ia menjadi sangat takut kehilangan putranya. la mengungkapkan perasaan tulusnya dengan kalimat $「 よ く$ 頑張った。よく頑張って、生きて、 母の元に」(Kau sudah berusaha keras. Kau sudah berusaha, dan kau hidup, kau kembali pada Ibu). Bagi Shige, akan ada jalan lain untuk Mineji meneruskan perjuangan Aizu.

Di balik sikap Shige sebelumnya yang sangat terkesan tanpa perasaan pada Mineji, pada kenyataannya Shige merupakan sosok sangat rapuh. Terdapat beberapa hal yang merefleksikan peran feminisme yang tercermin dalam diri Shige yaitu lebih dominan mengatur keluarga daripada sang suami, menjadi bagian dari perjuangan Klan Aizu dengan cara mendidik putranya secara tegas dan berusaha membantu para korban perang meskipun dirinya dalam kondisi sakit.

\section{Tokoh Wanita 2: Shinko}

Shinko adalah ibu dari Gisaburo yang merupakan sahabat Mineji. Sebagai ibu, karakter Shinko sangat berbeda dengan Shige. Shinko merupakan sosok ceria dan selalu bahagia. la sangat memanjakan Gisaburou dan selalu mengingatkan masa kecil Gisaburou sebagaimana kalimat yang selalu Shinko ucapkan「ねえ、あの小さな子を抱っこしたとは 夢のようじゃ」(Seperti mimpi masih memeluk anak itu). Meskipun kalimat tersebut terkesan 
menyenangkan, tetapi Shinko menyimpan perasaan bahwa lebih baik putranya selalu menjadi anak-anak dibanding menjadi seorang dewasa yang bisa saja terkena malang di medan perang.

Gisaburou terkadang merasa kerepotan karena ketika akan berangkat ke sekolah samurai, ia harus mendengarkan dahulu sang ibu berdendang. Kalimat ini merupakan nyanyian menidurkan anak kecil atau komamori uta 「ゆっくりお休み義三郎、目、目が覚め たらすいかをあげよう」(Tidurlah yang nyenyak Gisaburou. Saat matamu terbuka, kuberi semangka). Meskipun terkesan memperlakukan Gisaburou seperti anak-anak, Shinko bermaksud agar Gisaburou selalu merasa memiliki kenangan hidup menyenangkan yang akan ia bawa selama menjalani masa sulit bersama pasukan samurai muda Byakkotai.

Bagaimana karakter Shinko yang sesungguhnya tampak ketika perang benar-benar terjadi. Putra tersayang Shinko, Gisaburou dan para Byakkotai yang tengah ditugaskan untuk berperang, mengamati situasi wilayah Aizu dari atas bukit. Mereka melihat seluruh kota telah terbakar dipenuhi api. Para samurai muda tersebut meyakini bahwa Aizu telah kalah. Sebagaimana prinsip samurai untuk rela mati karena gagal mempertahankan Klan, maka mereka memilih untuk melakukan harakiri yaitu bunuh diri dengan cara menusuk dan merobek perut dengan pisau. Setelah beberapa waktu, seseorang menyampaikan kabar mengenai tewasnya para Byakkotai. Shinko pada saat mengetahui kabar tersebut sedang membantu di tempat evakuasi. Shinko berusaha tegar dan seolah telah mempersiapkan mental untuk hal terburuk terhadap sang putra. Shinko bahkan membesarkan hati Mineji yang berhasil selamat untuk terus bersemangat demi putranya, Gisaburou dan Byakkotai lainnya yang telah gugur. Jiwa besar Shinko tercermin pada kalimat berikut: 「峰地様、死ん でる義三郎たちより生きたあなたたちのほうがこれからは辛い過労。どうか皆の分まで、し っかり生きて、しっかり働いてくだされ。」(Tuan Mineji, daripada Gisaburou dan lainnya yang telah tiada, mulai sekarang perjuangan bagi kalian yang masih hiduplah yang lebih berat. Hiduplah dan bekerjalah dengan gigih demi mereka).

Di balik keceriaan Shinko, tersimpan kekuatan batin sebagai seorang ibu dan seorang wanita Aizu. Cerminan feminisme Shinko terlihat dari beberapa hal. Shinko tidak mengekang kehidupan Gisaburou seperti tidak melarang Gisaburou untuk jatuh cinta, meskipun hal tersebut terlarang bagi murid sekolah samurai. Shinko memilih berkontribusi mendidik seorang calon samurai dengan cara penuh kasih sayang, agar sang putra memiliki rasa percaya diri dan ketenangan jiwa. la tidak menolak kewajiban dan pengorbanan yang diemban putranya, oleh karena itu sebenarnya ia telah mempersiapkan gugurnya seorang pahlawan muda. Perjuangan Shinko selanjutnya adalah menjadi relawan untuk membantu warga Aizu.

\section{Tokoh wanita 3: Sayako}

Tokoh wanita muda bernama Sayako adalah salah satu dari sekelompok wanita yang gigih berlatih menggunakan pedang dan senapan. Ibu dari Sayako yang merupakan ahli pedang bernama Asai Sumie juga berlatih di tempat yang sama di bawah bimbingan Kakuma Sensei. Kakuma Sensei merupakan pengajar dan pelatih di sekolah samurai Nisshinkan. Secara kebetulan Mineji, Matahachi, dan Gisaburou memohon secara personal untuk dilatih menggunakan senapan, karena di sekolah mereka belum diperbolehkan. Namun, ketika mereka bertiga datang ke lokasi latihan, mereka sangat terkejut melihat bahwa semua yang dilatih Kakuma Sensei adalah wanita.

Murid-murid pria sekolah Samurai memiliki aturan larangan berbicara pada wanita selain keluarga dan wanita tertentu. Mineji, Matahachi, dan Gisaburo menolak berbicara pada wanita yang ada di lokasi latihan, dan hanya berbicara pada Kakuma Sensei. Bagi para samurai, berbicara pada wanita dapat merusak citra dan mengganggu tugas mulia mereka. Tetapi mereka tetap ingin dilatih, oleh karena itu para wanita tersebut mengajak mereka berlatih meskipun tanpa saling berbicara.

Sayako mendapatkan tugas melatih ketiganya. Sayako sangat mahir menggunakan pedang, dan meskipun baru berlatih senapan, ia sangat yakin dengan kemampuannya. Sayako berkata:「あなたたちの程度なら充分に教えることができるわ」(Jika hanya selevel 
kemampuan kalian, maka saya sudah cukup untuk mengajar kalian). Kalimat ini menunjukkan sikap feminis Sayako bahwa tidak hanya pria, wanita juga dapat diandalkan untuk melindungi Aizu.

Selanjutnya, antara Sayako dan Gisaburou saling menaruh hati. Perasaan yang tidak tersampaikan karena Gisaburou tidak diperbolehkan berbicara pada wanita. Gisaburou terkesan sangat malu, sedangkan Sayako dapat bersikap lebih lazim. Suatu hari ketika perang telah berlangsung dan Byakkotai akan dikirim ke medan perang, Sayako tidak berhasil menemui Gisaburou. la pun menitip pesan pada Mineji. Pesan yang disampaikan oleh Sayako menunjukkan sikap feminisme bahwa ia sebagai wanita lebih dahulu menyampaikan perasaan peduli dan dukungan. Sayako ingin Mineji menyerahkan boneka Daruma kecil sebagai jimat perlindungan pada Gisaburou. Hal ini menunjukkan adanya perasaan khusus Sayako terhadap Gisaburou. Sayako ingin Gisaburou tidak pernah menyerah layaknya filosofi boneka Daruma yang memiliki badan bulat tanpa kaki, sehingga tidak mungkin ada kata jatuh selain akan bangkit kembali.

Pertama, Sayako berpesan pada Mineji agar bersemangat. Pesan dari Sayako yaitu :

「しっかり戦ってください」(Bersungguh-sungguhlah bertarung). Kemudian, Sayako menitipkan pesan untuk Shinoda Gisaburou: 「〜これを篠田様にお渡しくださいませんか。 お守りです。〜ちょっと切られても、弾に当たっても、必ず受け上がれるように」(Tolong sampaikan ini pada Tuan Shinoda. Ini adalah o-mamori. Agar selalu dapat bangkit meskipun terkena pedang ataupun peluru). Sebagai wanita yang mencintai Gisaburou, ia tidak memiliki sedikitpun keraguan untuk melepaskan Gisaburou berperang.

Demikian pula Sayako sendiri telah mempersiapkan ritual bersama ibunya sebelum pergi berperang. Asai Sumie, sang ibu berkata bahwa ia akan memenggal kepala Sayako jika Sayako tampak akan jatuh ke tangan musuh, karena hal itu lebih terhormat. Tanpa ragu, Sayako mengatakan hal sebagai berikut：「敵の慰み者になって生きているより、母の手に て首をはねていただこうかどれほど幸せか分かりません」(Aku tidak tahu mana yang lebih membahagiakan, meminta ibu menebas leherku dengan tangan ibu atau hidup namun menjadi tawanan musuh). Sikap feminisme yang dikemukakan oleh keduanya berupa jiwa tidak takut mati, sementara manusia lazimnya takut akan mati. Tatkala Sayako terkena tembakan oleh musuh, sang ibu bergegas menebas leher Sayako. Tujuannya adalah agar nafas terakhir Sayako berhembus pada saat tebasan pedang dari tangan ibu sendiri, bukan dikarenakan peluru musuh.

\section{Tokoh wanita 4: Chieko}

Chieko merupakan istri salah satu penasehat pemimpin Klan Aizu yang bernama Saigo Tanomo. Chieko adalah sosok wanita yang sangat santun dan selalu mendukung setiap langkah dan prinsip sang suami. Saigo Tanomo merupakan penasihat pemereintahan yang sangat bijaksana. la tidak menyetujui keputusan untuk berperang, karena tidak ingin melihat rakyat Aizu bertumpah darah. Rekomendasi Saigo Tanomo kepada Pemimpin Klan Aizu, Matsudaira Katamori (Tono Sama) adalah tidak melakukan perang, namun bernegosiasi dengan musuh. Kemudian, Saigo Tanomo harus menanggung anggapan bahwa ia seorang pengecut. Chieko berperan membesarkan hati sang suami, menepis dengan bijak pandangan miring dari warga, dan memastikan keluarga untuk selalu hormat pada keputusan Saigo Tanomo. Pemikiran feminis yang melampaui pemikiran banyak pihak pada masa tersebut adalah bahwa Chieko meyakini pola pikir suaminya adalah pola pikir modern yang tak dapat diterima oleh masa itu.

Berikut ini adalah salah satu dialog yang menunjukkan karakter Chieko sebagaimana yang telah dijelaskan adalah sebagai berikut:「何も心配なっさいますな。あなたもこれま で危険なことのたびに反対なさって来られました。会津に限らず、どこのだれでも家族は平 和に暮らしたに決まっておりましょう。それをこの世の中でどうどうと口になさるあなたを 妻として誇りに思っております」(Jangan kuatirkan apapun. Engkau selama ini telah menentang hal yang membahayakan. Tidak hanya demi Aizu, pastinya agar seluruh keluarga siapapun dapat hidup dengan damai. Aku bangga padamu yang dengan lantang mengatakan hal itu kepada dunia). 
Gambaran hidup harmoni bagi Aizu telah terkoyak oleh pertempuran dan kekalahan Aizu. Menyadari hal tersebut, Chieko mengumpulkan seluruh anggota keluarganya di dalam suatu ruangan. Chieko memimpin upacara bunuh diri bersama bagi keluarganya. Chieko sebagai wanita Jepang yang memegang ideologi kehormatan, menjalankan tradisi samurai yaitu mati bunuh diri lebih terhormat daripada jatuh di tangan musuh.

5. Tokoh wanita 5: Teru Hime

Putri Teru atau Teru Hime merupakan adik dari pemimpin tertinggi Klan Aizu yaitu Matsudaira Katamori (Tono sama). Meskipun Teru Hime merupakan seorang wanita, tetapi secara demokratis keduanya dapat berdialog mengenai pemerintahan. la tidak sungkan untuk bertanya pada Tono sama ketika ada kesan terjadi permasalahan, seperti pada kalimat:「殿、何かございましたか。何か心を決まられましたね」(Tono, ada apa? Apakah ada yang sesuatu yang disimpan di hati?). Teru Hime memposisikan diri sebagai tempat di mana Tono sama dapat mencurahkan kegundahan. Sisi feminis Teru Hime pada konteks ini adalah sebagai wanita, ia juga menunjukkan pandangan mengenai perjuangan.

Ketika Tono sama akhirnya turut turun dalam medan perang, Teru Hime menyatakan bahwa ia akan bertanggung jawab melindungi istana.「この輝姫が留守はしっかり守りたい しますゆえ」(Teru Hime ini akan menjaga istana dengan baik selama Tono sama tidak ada). Melebihi janji menjaga istana, Teru Hime juga menjaga rakyat Aizu dengan cara menjadikan istana sebagai tempat perlindungan. Teru Hime berusaha keras memberikan pertolongan perobatan, makanan, dan hal lain yang diperlukan. Bahkan Teru Hime dengan ringan hati menggunakan kain-kain kimono yang berharga untuk membalut luka para korban. Pada situasi genting tersebut, Teru Hime berperan sebagai pemimpin yang memberikan perlindungan pada rakyatnya.

\section{Simpulan}

Berdasarkan analisis data, maka dapat disimpulkan beberapa hal sebagai berikut :

a. Terjadi transformasi gender dalam zaman patriarki. Dalam pengertian bahwa wanita berhak mengambil perannya secara terbuka demi bersama kaum pria menjaga kedaulatan Klan.

b. Ideologi samurai tidak hanya meresap dalam segenap jiwa kaum pria, melainkan juga kaum wanita.

c. Para tokoh wanita memiliki kepribadian, karakter, dan cara yang berbeda, namun mereka memiliki satu tujuan yaitu mempertahankan marwah Klan Aizu.

d. Penggunaan bahasa oleh para tokoh wanita menunjukkan adanya otoritas wanita sebagai individu.

e. Penggunaan bahasa oleh para tokoh wanita yang dikaji turut memperlihatkan konteks sosial dan budaya.

\section{Daftar Pustaka}

Elgin, Suzette H. 1982. Women and men speaking: frameworks for analysis by Cheris Kramarae. Retrieved from https://www.jstor.org/stable/413973

Holmes, Janet et.al. 2003. The handbook of language and gender. Berlin: Blackweil Publishing Lt.d

Lazar, M. Michelle. 2007. Feminist critical discourse analysis: Articulating feminist discourse praxis. Retrieved from https://doi.org/10.1080/ 
JPBJ, Vol. 7 No. 1, Februari 2021

ISSN: 2613-9618

\section{6}

Lehtonen, Sanna. 2007. Feminist critical discourse analysis and children's Fantasy fiction - modelling a new approach. Retrieved from https://www.researchgate.net/publication/242185953

Stokoe, E.H. \& Weatherall, A. 2002. Gender, language, conversation analysis and feminism. Retrieved from https://journals.sagepub.com doi/pdf/10.1177/0957926502013006751

Tracy, Sarah J. 2013. Qualitative research methods collecting evidence, crafting analysis, communicating impact. West Sussex: John Wiley \& Sons, Ltd

Titscher, Stefan. et al. 2009. Metode analisis teks dan wacana. Yogyakarta : Pustaka Pelajar 